\title{
Flight Performance and Competitive Displacement of Hummingbirds across Elevational Gradients
}

\author{
Douglas L. Altshuler \\ Bioengineering, California Institute of Technology, Pasadena, \\ California 91125 \\ Submitted September 24, 2004; Accepted September 15, 2005; \\ Electronically published December 12, 2005
}

\begin{abstract}
AвSTRACT: Hummingbirds, with their impressive flight ability and competitive aerial contests, make ideal candidates for applying a mechanistic approach to studying community structure. Because flight costs are influenced by abiotic factors that change systematically with altitude, elevational gradients provide natural experiments for hummingbird flight ecology. Prior attempts relied on wing disc loading (WDL) as a morphological surrogate for flight performance, but recent analyses indicate this variable does not influence either territorial behavior or competitive ability. Aerodynamic power, by contrast, can be derived from direct measurements of performance and, like WDL, declines across elevations. Here, I demonstrate for a diverse community of Andean hummingbirds that burst aerodynamic power is associated with territorial behavior. Along a second elevational gradient in Colorado, I tested for correlated changes in aerodynamic power and competitive ability in two territorial hummingbirds. This behavioral analysis revealed that short-winged Selasphorus rufus males are dominant over long-winged Selasphorus platycercus males at low elevations but that the roles are reversed at higher elevations. Several lines of evidence support the hypothesis that the burst rather than sustained aerodynamic performance mediates competitive ability at high elevation. A minimum value for burst power may be required for successful competition, but other maneuverability features gain importance when all competitors have sufficient muscle power, as occurs at low elevations.
\end{abstract}

Keywords: aerodynamic power requirements, burst performance, community structure, elevation, flight behavior, mechanistic approach.

The mechanistic approach to studying community ecology endeavors to link performance features of individual organisms with patterns of species interactions (Price 1986; Schoener 1986). Locomotor performance is believed to be

\footnotetext{
* E-mail: doug@caltech.edu.
}

Am. Nat. 2006. Vol. 167, pp. 216-229. (c) 2006 by The University of Chicago. 0003-0147/2006/16702-40647\$15.00. All rights reserved. an important determinant of competitive interactions among vagile animals, but testing this hypothesis is challenging because it requires both ecological and ecologically relevant biomechanical data. Consequently, attempts to study the effects of locomotor performance on community structure have been traditionally restricted to surrogate performance characters such as morphology (Feinsinger and Chaplin 1975; Price 1986). Techniques for measuring locomotor performance have improved considerably in recent years, and several investigators have now clearly demonstrated correlations between social rank within species and physiological features related to locomotor ability (Garland et al. 1990; Hammond et al. 2000; Perry et al. 2004). However, comparing the locomotor performance of interacting species to infer patterns of community structure has remained a formidable task because of the difficulty of attaining meaningful measures of locomotor ability for multiple interacting taxa. In comparative physiology, a highly productive line of research has been to focus on maximum capacities and limiting traits to reach mechanistic understanding of physiological design (Taylor and Weibel 1981). The hovering flight of hummingbirds has proven to be particularly amenable for assessing safety margins in response to both metabolic and aerodynamic challenges (Chai and Dudley 1995, 1996; Chai et al. 1997, 1999; Altshuler and Dudley 2003).

Dominance among hummingbirds is most frequently determined from observations of chases (Feinsinger 1976; DesGranges 1978; Kodric-Brown and Brown 1978; Kuban and Neill 1980; Feinsinger et al. 1985; Altshuler et al. $2004 b$ ), but a potential problem with this classification technique is that success in an aerial chase does not necessarily correlate with success in competition for food or mates. Pimm et al. (1985) introduced an alternative strategy for studying hummingbird competition that directly measures success at feeding territories. Hummingbirds are provided access to feeders differing in sugar concentrations, and the proportion of time each species is able to feed from the preferred feeders is used as an index of competitive dominance. This approach has allowed for distinguishing changes in competitive behavior among 
taxa for a suite of experimental variables involving competitor densities and information about feeder quality (Pimm et al. 1985; Mitchell 1989; Sandlin 2000).

In this study, I have tested for correlated changes in hummingbird flight performance and both territorial behavior and competitive ability at feeding territories across two elevational gradients. The first component of the study is a multispecies comparison of Andean hummingbirds from eight sites in southeastern Peru, spanning an elevational range of $\sim 3,500 \mathrm{~m}$. Using behavioral observations, I classified the taxa at each site into one of six foraging roles for hummingbirds described by Feinsinger and Colwell (1978). However, these data were reduced to territorial versus nonterritorial behavior to allow for comparisons across elevations. The flight performance of Peruvian hummingbirds was measured using a load-lifting protocol to assess the maximum short-term performance, also known as burst capacity (Chai et al. 1997). A larger analysis of the biomechanical data has been published previously (Altshuler et al. 2004c).

The second component of the study is a focal analysis of two species of territorial hummingbirds at two elevations in the Colorado Rocky Mountains. During summer months, broad-tailed hummingbirds Selasphorus platycercus breed in the Rockies. In late summer, migrants of congeneric rufus hummingbirds Selasphorus rufus cooccur with $S$. platycercus at elevations from 1,600 to 3,000 $\mathrm{m}$, competing with residents for access to floral nectar (Miller and Inouye 1983). The body mass of migratory hummingbirds fluctuates considerably during stopovers (Carpenter et al. 1983, 1993a), but average values are similar for the two taxa (Calder and Calder 1992; Calder 1993; Altshuler and Dudley 2003). In contrast, S. platycercus have considerably longer wings and thus lower wing disc loading (WDL) than S. rufus (Calder and Calder 1992; Calder 1993; Altshuler and Dudley 2003). Competitive interactions between these closely related species have been studied through observations of chases at the lower to midelevational ranges $(2,072-2,650 \mathrm{~m})$ where they co-occur, and S. rufus is most often the dominant competitor (Feinsinger and Chaplin 1975; Kodric-Brown and Brown 1978). However, even at the lower end of this elevation range $(\sim 2,100 \mathrm{~m})$, S. platycercus can be dominant or only marginally less successful than S. rufus (Dunford and Dunford 1972; Kuban and Neill 1980). The competitive interactions between the two species have not been studied at the higher elevations where they co-occur.

In examining the prediction of elevational shifts in competitive ability, I also sought to determine its mechanistic basis through observing and measuring flight performance. I studied flight behavior during competitive bouts for access to feeders and quantified the use of different flight modes between taxa. To examine which features of hummingbird flight affect their competitive behavior, I also performed three laboratory experiments evaluating aspects of flight performance known to vary with elevation: maximum short-term (burst) power capacity as measured through load-lifting, sustained hovering ability in lowdensity air, and sustained hovering ability in hypoxia.

\section{Methods}

Behavioral Observations in the Peruvian Andes

The competitive and nectar-foraging behaviors of Peruvian hummingbirds were studied in 1998 and 1999 at eight field sites in the Departments of Cusco and Madre de Dios, Peru. Observations were made primarily at flower patches because the hummingbirds in this region were unaccustomed to artificial feeders. However, at the San Pedro site located in cloud forest at $1,480 \mathrm{~m}$, the hummingbirds regularly visited artificial feeders, and these observations were included as well. Formal observations lasted for $1 \mathrm{~h}$, during which all chases were recorded, as was the time spent feeding and the time on the territory. Feeding time was defined as the duration that each bird maintained its bill in the flower or feeder, and time on the territory was defined as both time spent perching and time spent feeding at the territory site (Pimm et al. 1985). Two or more individuals of the same taxon were counted as one if these occurred during the same period. Time on territory began when a hummingbird came within $8 \mathrm{~m}$ of the focal flower patch or feeder. In addition to the $1-\mathrm{h}$ formal observations, informal observations were also made of varying lengths including records consisting only of chases. The complete tally of recorded chases from informal and formal observations is presented elsewhere (Altshuler et al. 2004b).

The timed behaviors and the chases were combined to estimate the community role of Peruvian hummingbirds at each of the sites. Descriptions of these roles are given by Feinsinger and Colwell (1978), and I quantitatively determined community role according to the criteria given in table 1. Data from different observations were pooled for role assignment, but taxa with variable data were classified as "generalists" because these appeared to opportunistically fill roles according to which competitors were present during a given observation period. Because not all roles were filled at all elevations, the behavioral categories were simplified to territorial and nonterritorial hummingbirds.

\section{Behavioral Observations in the Colorado Rockies}

Observations in the Colorado Rockies were recorded in 1998 and 1999 at two sites near the elevational limits for the range where Selasphorus platycercus and Selasphorus rufus overlap. The low-elevation site was Cheyenne Canyon Park 
Table 1: Criteria for determining the community roles of Peruvian hummingbirds

\begin{tabular}{lcclc}
\hline Role & Time on site $(\mathrm{min})$ & Feeding $(\%)$ & Chases & Bill size \\
\hline Territorialist & $>10$ & $<30$ & Chaser & Not large \\
Marauder & $<10$ & $>50$ & Chaser & Not large \\
Filcher & $<10$ & $>50$ & Target & Not large \\
High-reward trapliner & $<10$ & $>50$ & Few or no encounters & Large \\
Low-reward trapliner & $<10$ & $>50$ & Few or no encounters & Not large \\
Generalist & $<10$ & Variable & Chaser and target & Not large \\
\hline
\end{tabular}

Note: Values for time on site and feeding time were measured during 60-min observation periods, but chases were recorded during these formal observations as well as from other encounters that were observed opportunistically. On the basis of descriptions from Feinsinger and Colwell (1978), territorial hummingbirds were expected to spend long periods of time at flower patches and feeders, feeding occasionally and chasing intruders. Nonterritorial hummingbirds entered the flower patches or feeder area only to feed but differed according to bill size and chase behavior.

outside of Colorado Springs at an elevation of $1,875 \mathrm{~m}$. It has an average air density of $0.987 \mathrm{~kg} / \mathrm{m}^{3}$ and an oxygen partial pressure of $128.3 \mathrm{~mm} \mathrm{Hg}$. The high-elevation site was the Rocky Mountain Biological Laboratory in Gothic, located at 2,900 $\mathrm{m}$. It has an average air density of 0.862 $\mathrm{kg} / \mathrm{m}^{3}$ and an oxygen partial pressure of $112.1 \mathrm{~mm} \mathrm{Hg}$.

Hummingbird feeding and flight behaviors were studied at artificial feeders in open meadows and surrounding scrub at both sites. The feeders were placed in pairs containing one "high-quality" feeder (1.20 M sucrose) and one "low-quality" feeder ( $0.38 \mathrm{M}$ sucrose). Sucrose molarities of naturally occurring hummingbird flowers range from 0.35 to $1.0 \mathrm{M}$ (Baker 1975), and preference for high sugar concentrations ( $>1.4 \mathrm{M}$ sucrose) has been documented through both laboratory and field preference tests (Roberts 1996; Blem et al. 2000).

The two feeders within a pair were separated by $50-75$ $\mathrm{m}$ so that no individual bird could dominate both simultaneously. Three pairs of feeders were placed at each site, and the paired feeders were separated linearly by at least $100 \mathrm{~m}$. Both feeders within a pair were observed simultaneously for 30-min periods by at least two and as many as four researchers. Morning observations occurred between 6:00 and 10:00 a.m., and afternoon observations occurred between 3:30 and 8:30 p.m. A feeder pair was observed either once or twice a day, in the morning, afternoon, or both. During July and August of 1998 and 1999, 185 observations of feeder pairs were recorded. Competitive dominance was estimated using the selectivity index, which is defined as the time spent feeding (definition as above) at the high-quality feeders divided by the overall time spent feeding from both feeders (Sandlin 2000). In the field observations, hummingbirds were categorized into three species/gender classes: $S$. platycercus males, S. rufus males, and females of both species were combined for analysis. Not all observers could distinguish the females of both species in the field, but the available data indicate that most of the females at the feeders were S. rufus.
Competitor density for a given class was defined as the amount of time members of competing species/gender classes spent in a territory (territory definition as above). Competitor densities were assigned to the low category if competitor hummingbirds were present $<55 \%$ of the 30 min observation period, and they were assigned to the high category if competitors were present $>75 \%$ of the observation period. These values were determined from the bimodal distribution of the competitor density values. No competitor density values were measured between 55\% and $75 \%$, justifying the segregation into these two groups. The independent variables proposed to affect selectivity include species and gender class, elevation, and competitor density. These relationships were tested with a three-way ANOVA.

In 1998, I qualitatively observed hummingbird flight behavior during competitive encounters and noticed that hummingbird flight modes could be classified into three discrete categories: forward flight, hovering, and vertical ascent. In aerial encounters, intruding hummingbirds were ultimately chased off territories using forward flight. Because feeders were placed on PVC tubes at heights equivalent to the surrounding vegetation, territorial defense flights did not require any vertical component before a chase. Nonetheless, the chases were often bounded by contests that involved hovering and/or rapid vertical ascents, both of which require elevated vertical force production relative to forward flight. Gaining vertical elevation rapidly allowed the higher bird to attack from above. In 1999, I recorded the time hummingbirds spent in forward flight chases versus the time engaged in hovering and vertical ascent (combined) during competitive encounters in the 30-min observation periods. The analysis includes competitive encounters in 289 observation periods, with observations at rich and poor feeders counted separately. The data were analyzed using a ratio termed the "vertical flight index," which is defined as the time spent in hovering and vertical ascent divided by the total time spent in competitive flight. I performed the analysis with a three-way 
ANOVA in which elevation, species/gender, and feeder type served as the independent variables.

\section{Burst Flight Performance}

The burst performance of hummingbirds from both the Andes and the Rockies was studied during the same periods as the behavioral observations and using the technique of transient load lifting (Chai and Millard 1997; Chai et al. 1997). An analysis of the load-lifting performance of the Andean taxa has been published previously (Altshuler et al. 2004c), and only a brief description of the protocol will be given below. Complete load-lifting data were available for 347 individual Peruvian hummingbirds from 43 taxa, but corresponding behavioral data were available for only a subset of these (see "Results"). In the Colorado Rockies, the load-lifting performance of four $S$. platycercus males, five S. rufus males, and 10 S. rufus females from the Rocky Mountain Biological Laboratory were compared with five of each species/gender class from Cheyenne Canyon.

A chain of color-coded weights was attached to a harness that was placed around a hummingbird's neck. Upon release from the floor of the chamber, the birds' natural escape response was to fly upward, thus lifting progressively more weight with increasing height. Once reaching their maximum load, the hummingbirds hovered briefly before descending to the floor or wall. Following loadlifting trails, each individual was also filmed during free hovering flight.

Flights were filmed in a chamber $(0.5 \mathrm{~m} \times 0.5 \mathrm{~m} \times$ $1 \mathrm{~m}$ ) made with PVC scaffolding and four sides covered in nylon mesh. A sheet of clear acrylic covered the top of the chamber, and a mirror was suspended above at an angle of $45^{\circ}$ relative to the chamber ceiling. One camera (Sony Video 8 CCD-TR44) filmed the mirror and thus recorded the horizontal projections of wing motions. During the load-lifting trials, a second synchronized color camera (Sony 8XR CCD-TRV16) filmed the portion of the weight chain remaining on the chamber floor, and thus by subtraction, the weight lifted. Frame-by-frame analysis of video films allowed for measurement of the stroke amplitude of the wings and the wingbeat frequency (see Chai and Dudley 1996; Altshuler and Dudley 2003). Calculating accurate stroke amplitudes through this single view was possible because hummingbirds hover with a stroke plane angle near $0^{\circ}$ (Stolpe and Zimmer 1939; Chai and Dudley 1996). Wingbeat kinematics, physical properties of the air, and morphological characteristics of each bird were used to calculate body mass-specific aerodynamic power output (Ellington 1984f; Wells 1993).

The data from the Peruvian Andes were analyzed using general linear models comparing the WDL and the burst aerodynamic power of territorial and nonterritorial taxa across elevations. The performance of Selasphorus hummingbirds from Colorado was tested using three-way ANOVAs for effects of species/gender group, elevation, and flight mode (free hovering vs. maximum load lifting) on kinematic variables and the aerodynamic power output.

\section{Sustained Hovering Performance}

Sustained hovering performance in response to aerodynamic and metabolic challenges was studied for the Selasphorus hummingbirds from Colorado only. Experiments in hypodense or hypoxic air were accomplished using physically variable gas mixtures (Dudley and Chai 1996) at both elevations. Twenty-four individual hummingbirds were tested, evenly divided as follows: four male $S$. platycercus, four male S. rufus, and four female $S$. rufus per site. Females of $S$. platycercus were not used for gas mixture experiments because these birds were breeding during the study period (see Altshuler and Dudley 2003). All of the hummingbirds used in the gas infusion experiments were tested for both conditions as well as for load-lifting ability.

Infusion of either normoxic heliox $\left(\rho=0.41 \mathrm{~kg} / \mathrm{m}^{3}\right.$ at sea level) or pure nitrogen $\left(\rho=1.165 \mathrm{~kg} / \mathrm{m}^{3}\right.$ at sea level $)$ into a sealed flight chamber $(0.5 \mathrm{~m}$ diameter; $1 \mathrm{~m}$ tall $)$ lowered either the air density or the oxygen concentration while keeping the other variable near constant. During trials, air density was determined acoustically by analyzing the frequency changes of a whistle (Dudley 1995), barometric pressure was taken from climate data collected at each site, and instantaneous oxygen concentration of the mixture was recorded from an oxygen monitor (GC Industries GC 501). Birds were encouraged to hover by retracting their perch every $5 \mathrm{~min}$, and trials progressed until the birds could no longer sustain hovering flight. At this point, the experiments were terminated, and normal air was allowed back into the chamber.

Wingbeat kinematics during hovering were obtained by a video camera (Sony Video 8 CCD-TR44) and combined with morphological and environmental measurements to estimate aerodynamic power requirements as described above. In each of the two experiments with manipulated gases, a three-way repeated-measures ANOVA was used to test the effects of species/gender class, elevation, and environmental variables (with the repeated measure being either air density or oxygen concentration) on the aerodynamic power output during sustained hovering flight.

\section{Results}

\section{Flight Performance and Territorial Behavior of Peruvian Hummingbirds}

Behavioral observations were made for 29 hummingbird taxa in Peru with sufficient data for classification into one 
Table 2: Wing disc loading $\left(\mathrm{WDL}_{\mathrm{A}}, \mathrm{g} / \mathrm{cm}^{2}\right)$, maximum aerodynamic power $\left(P_{\text {aero, max }}, \mathrm{W} / \mathrm{kg}\right.$ body mass specific), and community role of hummingbirds from eight sites along an elevational gradient in southeast Peru

\begin{tabular}{|c|c|c|c|c|}
\hline Taxon & $n$ & $\mathrm{WDL}_{\mathrm{A}}$ & $P_{\text {aero, } \max }$ & Community role \\
\hline \multicolumn{5}{|l|}{ Pantiacolla $(400 \mathrm{~m}):$} \\
\hline Campylopterus largipennis & 10 & .0468 & 144.08 & Territorialist (marauder) \\
\hline Chloristilbon mellisugus & 1 & .0428 & 141.51 & Filcher \\
\hline Phaethornis malaris & 6 & .0524 & 101.96 & High-reward trapliner \\
\hline Thalurania furcata & 6 & .0564 & 117.75 & Generalist \\
\hline Threnetes niger & 9 & .0517 & 100.35 & High-reward trapliner (territorialist) \\
\hline \multicolumn{5}{|l|}{ Amazonia $(500 \mathrm{~m})$ : } \\
\hline C. largipennis & 8 & .0508 & 132.21 & Generalist \\
\hline C. mellisugus & 3 & .0545 & 88.99 & Low-reward trapliner \\
\hline Chrysuronia oeneae & 8 & .0591 & 106.61 & Territorialist \\
\hline Colibri coruscans & 8 & .0456 & 110.79 & Marauder \\
\hline Florisuga mellivora & 8 & .0535 & 120.29 & Marauder \\
\hline Glaucis hirsuta & 5 & .0560 & 108.05 & High-reward trapliner \\
\hline Heliodoxa aurescens & 2 & .0516 & 156.25 & Low-reward trapliner \\
\hline Lophornia delattrei & 2 & .0738 & 89.13 & Filcher \\
\hline Phaethornis keopckeae & 12 & .0454 & 97.67 & High-reward trapliner (generalist) \\
\hline P. malaris & 6 & .0468 & 99.16 & High-reward trapliner \\
\hline T. furcata & 14 & .0502 & 106.23 & Generalist \\
\hline T. niger & 11 & .0518 & 95.18 & High-reward trapliner \\
\hline \multicolumn{5}{|l|}{ San Pedro $(1,480 \mathrm{~m})$ : } \\
\hline Adelomyia melanogenys & 8 & .0431 & 109.09 & Generalist \\
\hline Aglaiocercus kingi & 2 & .0408 & 112.49 & Generalist \\
\hline Heliodoxa leadbeateri & 10 & .0498 & 137.71 & Territorialist \\
\hline Ocreatus underwoodii & 5 & .0551 & 126.14 & Filcher (low-reward trapliner) \\
\hline \multicolumn{5}{|l|}{ Pillahuata $(2,650 \mathrm{~m})$ : } \\
\hline Agleactis cupripennis & 6 & .0331 & 117.07 & Territorialist, filcher \\
\hline Boissonneaua matthewsii & 1 & .0449 & 99.56 & Territorialist \\
\hline Coeligina violifer & 8 & .0462 & 103.77 & Filcher \\
\hline Heliangulus amethysticollis & 7 & .0459 & 102.80 & Territorialist \\
\hline Lafresnaya lafresnayi & 1 & .0420 & 147.22 & Territorialist (filcher) \\
\hline Metallura tyrianthia & 12 & .0416 & 97.50 & Generalist \\
\hline \multicolumn{5}{|l|}{ Huarcarpay $(3,090 \mathrm{~m})$ : } \\
\hline C. coruscans & 4 & .0519 & 100.52 & Territorialist \\
\hline Lesbia nuna & 2 & .0547 & 80.69 & Filcher \\
\hline Oreonympha nobilis & 4 & .0395 & 77.42 & Territorialist \\
\hline Patagona gigas & 2 & .0387 & 101.36 & Territorialist \\
\hline \multicolumn{5}{|l|}{ Canchayoc $(3,650 \mathrm{~m})$ : } \\
\hline Agleactis castenauldi & 2 & .0384 & 99.23 & Territorialist \\
\hline A. cupripennis & 6 & .0396 & 126.06 & Territorialist \\
\hline C. violifer & 1 & .0414 & 86.99 & Territorialist \\
\hline Metellura aeneocauda & 14 & .0508 & 100.47 & Territorialist \\
\hline M. tyrianthina & 10 & .0460 & 101.04 & Generalist \\
\hline \multicolumn{5}{|l|}{ Cachimayo $(3,665 \mathrm{~m})$ : } \\
\hline A. cupripennis & $0^{\mathrm{a}}$ & .0396 & $126.06^{\mathrm{a}}$ & Territorialist (marauder) \\
\hline C. coruscans & 4 & .0481 & 104.51 & Filcher \\
\hline L. nuna & 4 & .0459 & 115.09 & Generalist \\
\hline O. nobilis & 2 & .0410 & 75.02 & Generalist \\
\hline \multicolumn{5}{|l|}{ Huancarani $(3,860 \mathrm{~m})$ : } \\
\hline C. coruscans & 1 & .0473 & 64.72 & Generalist \\
\hline Oreotrochilus estella & 5 & .0567 & 89.64 & Territorialist \\
\hline
\end{tabular}

Note: Values for $\mathrm{WDL}_{\mathrm{A}}$ and $P_{\text {aero, max }}$ were calculated from the data sets of Altshuler et al. $(2004 b, 2004 c)$, with site-specific data presented here. Sample sizes $(n)$ are for the total number of individuals of each taxon at each site for which aerodynamic power data were available. Community roles were determined from criteria given in table 1, with primary role presented first and secondary role in parentheses. All analyses involving the Peru community were performed with and without the inclusion of the hummingbirds from Cachimayo, but this had no influence on the significance of either main or interaction effects.

a The burst power values from A. cupripennis that were attained at Canchayoc $(3,660 \mathrm{~m})$ were also used for analyses with that taxon at Cachimayo $(3,665 \mathrm{~m})$ because complete kinematics data were not available. 
Table 3: Results from general linear models testing the effects of territoriality and elevation on the wing disc loading and maximum power production of hummingbirds in the Andes of southeastern Peru

\begin{tabular}{lrrrr}
\hline Source & $\mathrm{df}$ & \multicolumn{1}{c}{ MSE } & \multicolumn{1}{c}{$F$} & \multicolumn{1}{c}{$P$} \\
\hline Wing disc loading: & & & & \\
$\quad$ Territoriality & 1 & $2.795 \times 10^{-5}$ & .628 & .433 \\
$\quad$ Elevation & 1 & $2.398 \times 10^{-4}$ & 5.387 & .026 \\
$\quad$ Territoriality $\times$ elevation & 1 & $2.740 \times 10^{-6}$ & .062 & .806 \\
$\quad$ Error & 38 & $4.452 \times 10^{-5}$ & & \\
Maximum power: & & & & \\
$\quad$ Territoriality & 1 & $1,485.579$ & 4.421 & .042 \\
$\quad$ Elevation & 1 & $3,032.506$ & 9.025 & $<.005$ \\
$\quad$ Territoriality $\times$ elevation & 1 & 81.049 & .2412 & .626 \\
$\quad$ Error & 38 & 336.031 & & \\
\hline
\end{tabular}

Note: MSE $=$ mean squared error.

of the community roles defined by Feinsinger and Colwell (1978). Eight of these taxa occurred at two sites, one taxon occurred at three sites, and a fourth hummingbird Colibri coruscans was present at four sites. The hummingbirds, their community role, WDL, and maximum short-term (burst) power output at each site are presented in table 2. Because many of the community roles were not fulfilled at the high-elevation sites, the analysis was restricted to territorial versus nonterritorial hummingbirds (pooled by primary role). WDL decreased across elevations but did not differ between territorial and nonterritorial hummingbirds (table 3). Burst power output also decreased with increasing elevation, as was reported previously for the power margin (ratio of burst power output to the power output of sustained hovering) of a larger sample of Peruvian hummingbirds (Altshuler et al. 2004c). Unlike WDL, burst power output was influenced by community role (table 3). Specifically, territorial hummingbirds can produce significantly more burst power than nonterritorial taxa (fig. 1).

\section{Competitive Interactions of Colorado Hummingbirds}

During some of the feeder observation periods, one abundant species/gender class would occupy both rich and poor feeder territories either because those hummingbirds were highly dominant or because no other competitor classes were present at the feeder pair. During these observations, selectivity values would be at $50 \%$, indicating equal feeding from both rich and poor feeders. When competitor densities were low, all species/gender classes had selectivity values greater than or equal to $50 \%$ (fig. $2 \mathrm{~A}$ ), indicating preference for the rich feeders. At high competitor densities, males of Selasphorus rufus displayed high selectivity at $1,875 \mathrm{~m}$ but low selectivity at $2,900 \mathrm{~m}$, whereas males of Selasphorus platycercus exhibited low selectivity at 1,875 $\mathrm{m}$ and high selectivity at $2,900 \mathrm{~m}$ (fig. $2 \mathrm{~A}$ ). The ANOVA revealed a significant interaction effect among all three independent variables (table 4). Specifically, S. platycercus males were subordinate at low elevations and dominant at high elevations. Selasphorus rufus males displayed the opposite pattern.

During competitive flights, all hummingbirds used forward flight chases but exhibited interspecific differences in their use of forward flight, hovering, and vertical ascent (fig. $2 B$ ). The variance in the vertical flight index was explained by the species/gender class $(F=8.285, \mathrm{df}=$ $2,277, P<.001)$. Specifically, $S$. platycercus males spent more time in hovering and vertical ascent than the other classes of hummingbirds. However, the interaction effect between hummingbird class and elevation was not significant $(F=1.7566, \mathrm{df}=2,277, P=.1745)$.

\section{Flight Performance of Colorado Hummingbirds}

During maximal lifts, hummingbirds increased wingbeat frequency by an average of $17 \%$ for all classes at both sites (fig. $3 A$ ). Because the three classes of hummingbirds also differed in their baseline wingbeat frequency for hovering (Altshuler and Dudley 2003), there were two significant effects in the ANOVA for wingbeat frequency: species/ gender class $(F=193.1221, \mathrm{df}=2,52, P<.0001)$ and flight mode $(F=135.7379, \mathrm{df}=1,52, P<.0001)$. None

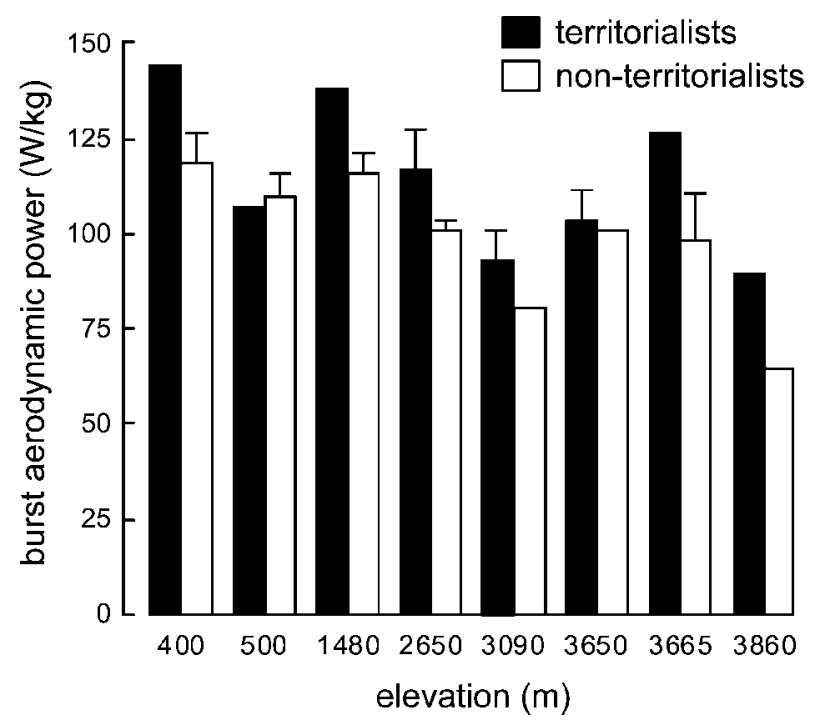

Figure 1: Burst aerodynamic power (body mass specific) of territorial and nonterritorial hummingbirds from different elevations in southeast Peru. Columns represent mean values for all taxa in each category, and bars represent SE about the mean. All estimates of aerodynamic power reported here use an empirically derived profile drag coefficient of 0.139 (Altshuler et al. 2004a). 

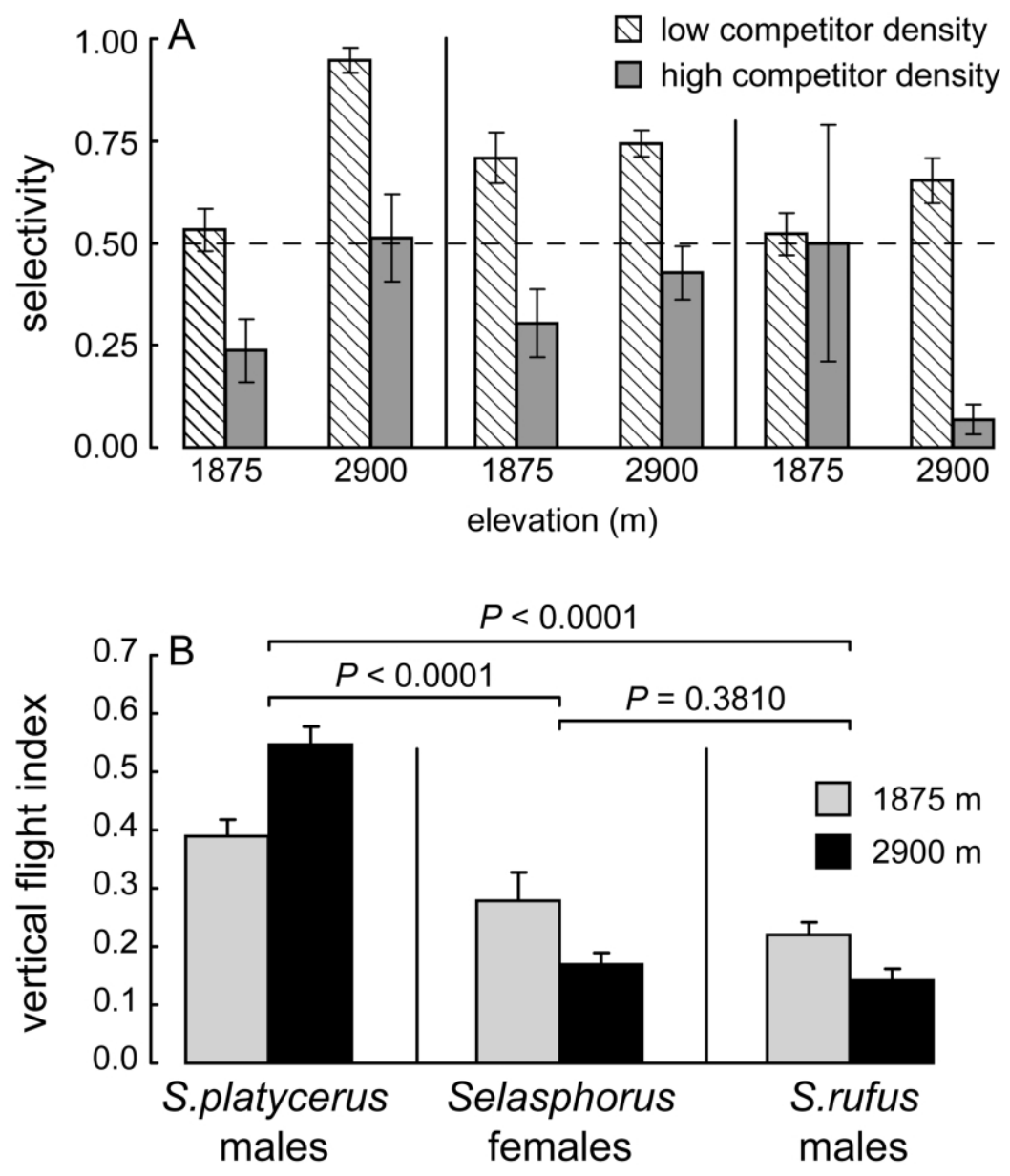

Figure 2: Changes in hummingbird competitive behavior across elevations in the Colorado Rockies. Selectivity is the ratio of time spent feeding from the rich sucrose feeders divided by the overall time spent feeding $(A)$. The first four columns represent the data for Selasphorus platycercus males, followed by four columns for Selasphorus females of both species, followed by four columns for Selasphorus rufus males. Columns are mean values of selectivity, with bars representing SE about the mean. The dashed line indicates selectivity of $50 \%$. The vertical flight index is the ratio of the time spent hovering or in vertical ascent during competitive encounters divided by the overall time spent in competitive aerial encounters $(B)$. Probability values refer to differences between species/gender classes.

of the interaction effects were significant, indicating that the hummingbirds did not differ in how they modulated wingbeat frequency with respect to changes in elevation or mode of flight.

Several studies have documented for multiple species that hummingbirds generate maximal vertical force when they have increased stroke amplitude for each wing to a value near $180^{\circ}$ (Chai and Dudley 1995; Chai and Millard 1997; Altshuler and Dudley 2003), and the Colorado Selasphorus hummingbirds met this prediction during maximum load lifting (fig. $3 B$ ). In addition, the species/gender classes differed in their baseline requirements for hovering stroke amplitudes and used higher stroke amplitudes at the high-elevation site (table 5). Furthermore, the ANOVA revealed a significant interaction effect between hum- mingbird class and flight mode (table 5). Because S. rufus males require higher stroke amplitudes to hover, these hummingbirds have reduced kinematic ability to modulate aerodynamic forces relative to the other classes.

Aerodynamic power output was influenced by all three components of the ANOVA model, indicating that hummingbirds differed in their ability to generate maximum power across elevation (fig. $3 \mathrm{C}$ ). With respect to main effects, overall power production increased during load lifting and decreased across elevations (table 6). Two of the interaction effects were significant: hummingbird flight mode $\times$ elevation and flight mode $\times$ species/gender class (table 6). Specifically, all hummingbirds increased power production for normal hovering across elevations but had reduced burst power capacity at high elevations. Second, 
hummingbirds differed in their overall power output for both flight modes, with $S$. rufus males having the lowest aerodynamic power capacity.

During heliox replacement of normal air, density decreased systematically, and hummingbirds increased wing stroke amplitudes (Altshuler and Dudley 2003), leading to an overall increase in aerodynamic power output (fig. $4 A$; table 7 ). The hummingbird groups differed in their aerodynamic power requirements, with short-winged S. rufus males requiring the most power and long-winged S. platycercus males requiring the least. However, these differences among the species/gender classes were consistent across air densities, and none of the interaction effects with air density were significant (table 7 ).

During nitrogen replacement of normal air, oxygen partial pressure decreased, and hummingbirds lowered wingbeat frequency (Altshuler and Dudley 2003), leading to an overall decrease in aerodynamic power production (fig. $4 B$; table 8 ). The species/gender classes also differed in their aerodynamic power output, but again, no interaction effects with oxygen partial pressures were detected (table $8)$.

\section{Discussion}

The influence of flight performance on competitive interactions has been an active area of investigation for hummingbird ecology, although previous analyses have relied on morphological inference rather than biomechanical analysis of flight. The central hypothesis has been that territorial behavior and competitive superiority increase with high values of WDL (Feinsinger and Chaplin 1975; Feinsinger and Colwell 1978; Kodric-Brown and Brown 1978; Carpenter et al. 1993b, 1993c). A second motivating concept was that, among taxa, WDL decreases across elevations (Feinsinger et al. 1979), a finding that has subsequently been substantiated with phylogenetic correction (Altshuler and Dudley 2002). Accordingly, hummingbirds with broad elevational ranges tend to encounter competitors with relatively smaller wings and higher WDL on the lower end of their range and with relatively larger wings and lower WDL on the upper end of their range. Combining this observation with their hypothesis for the role of WDL in competitive ability led to the prediction that hummingbirds should be more competitively successful at the upper end of their elevational range (Feinsinger et al. 1979). My colleagues and I conducted a pooled analysis from multiple studies with broad taxonomic sampling and concluded that the hypotheses linking high WDL to territorial behavior and competitive ability are not supported (Altshuler et al. 2004b; this study). Thus, any relationship between behavioral ecology and features of flight performance related to elevation should involve other metrics.
Burst aerodynamic power, unlike WDL, is significantly correlated with territorial behavior. Specifically, the Peruvian hummingbird species that held territories and chased intruders could produce higher maximum power than taxa fulfilling nonterritorial community roles (fig. 1). This analysis required lumping all of the nonterritorial community roles into one and thus potentially obscured important differences among foraging strategies. In particular, the "marauder" behavior is essentially dominant to the territorial hummingbirds, but only several taxa could fulfill this role, mostly at lower elevations. Nonetheless, combining the nonterritorial roles is likely to weaken rather than strengthen the conclusion relating burst power to territorial behavior. In this and a previous study (Altshuler et al. 2004c), a significant decline in power availability with increasing elevation was observed. Thus, comparing the power output and competitive abilities of the same territorial species across elevations provides a powerful natural experiment for elucidating the relationship between flight performance and competitive ability, as originally proposed by Feinsinger et al. (1979).

For two species of territorial hummingbirds in the Colorado Rockies, success at dominating the preferred resource shifted across elevations (fig. 2A). Long-winged Selasphorus platycercus males were subordinate to shortwinged Selasphorus rufus males at low elevations but were dominant at high elevations. Three aspects of flight performance were studied to determine which correlated best with changes in behavioral selectivity. Power requirements for sustained hovering varied among hummingbirds in both of the gas mixture experiments, but hummingbirds exhibited similar responses to experimental changes, as indicated by the absence of interaction effects with air density (table 7) and with oxygen availability (table 8). Burst performance, as measured through load lifting, differed among hummingbirds and across elevations (table 6). However, burst power alone cannot explain the transposition in dominance because the larger winged S. platy-

Table 4: Three-way ANOVA for the effects of species/gender class, elevation (m), and competitor density on the selectivity of Colorado hummingbirds

\begin{tabular}{lrrrr}
\hline Source & df & MSE & \multicolumn{1}{c}{$F$} & \multicolumn{1}{c}{$P$} \\
\hline Class & 2 & .252 & 2.171 & .116 \\
Elevation & 1 & .371 & 3.197 & .078 \\
Competitor density & 1 & 5.225 & 45.010 & $<.001$ \\
Class $\times$ elevation & 2 & .703 & 6.057 & .003 \\
Class $\times$ competitor density & 2 & .017 & .143 & .867 \\
Elevation $\times$ competitor density & 1 & .465 & 4.004 & .046 \\
Class $\times$ elevation $\times$ & & & & \\
$\quad$ competitor density & 2 & .496 & 4.27 & .015 \\
Error & 366 & .116 & & \\
\hline
\end{tabular}

Note: $\mathrm{MSE}=$ mean squared error. 


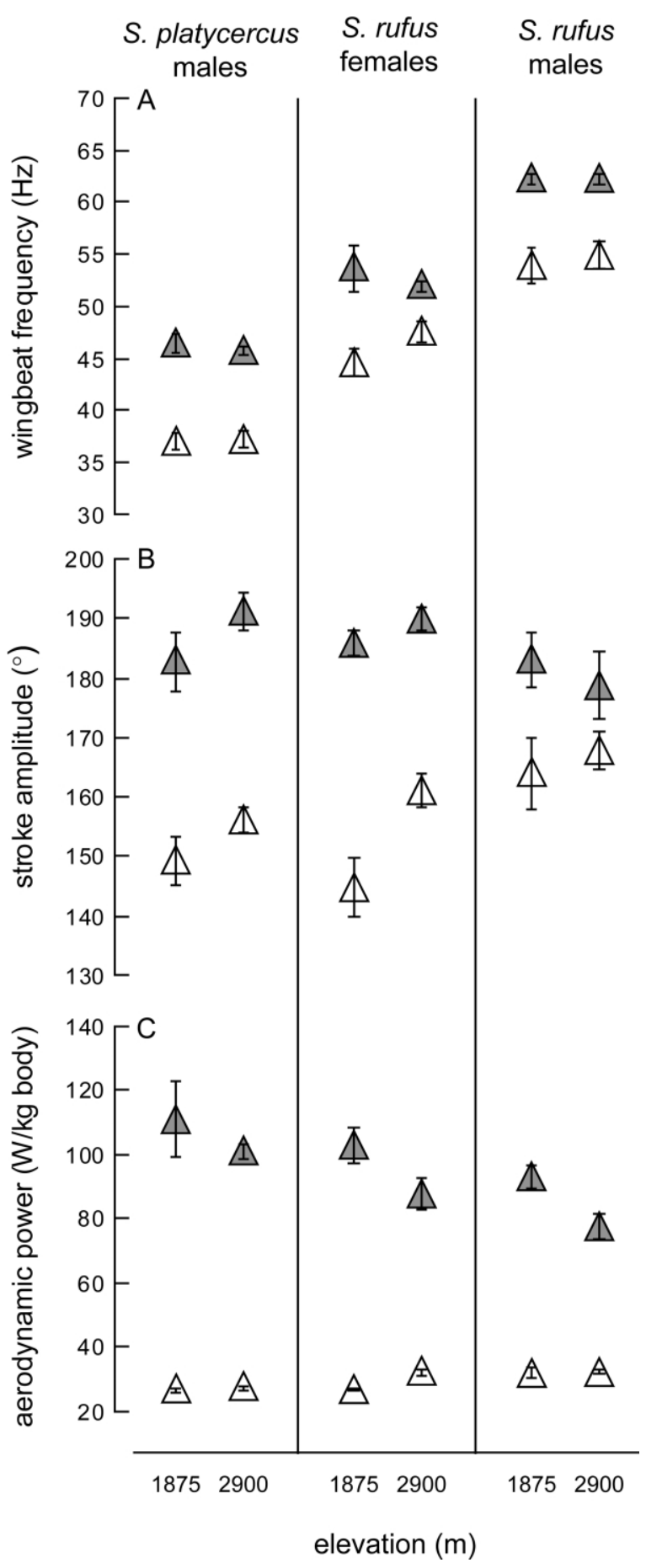

Figure 3: Kinematics and power output during free hovering (open triangles) and maximum load lifting (gray triangles) for hummingbirds in the Colorado Rockies. Triangles represent mean values, and bars represent $\mathrm{SE}$ about the mean. Selasphorus hummingbirds increased wingbeat frequency by an average of $17 \%$ for transient load lifting, but this kinematic variable was not modulated across elevations $(A)$. In contrast, these hummingbirds increased stroke amplitudes both during load lifting and at cercus exhibited more power availability at both elevations (fig. 3C). The effects of elevation on maximum power availability nonetheless resemble several aspects of how elevation influenced behavioral selectivity, and there are two scenarios under which burst power capacity could determine the outcome of these competitive interactions but only at high elevation. The first hypothesis is that there is an absolute threshold either for generating burst power in ascent or in features correlated with this performance metric. The second hypothesis is that a different threshold exists for the relative difference in burst power between competitors. Accordingly, S. rufus males would have been above either an absolute or a relative threshold at low elevations, where these hummingbirds could rely on other features of flight performance. Conversely, larger-winged S. platycercus could overpower their shorter-winged competitions at high elevations. A final possibility is that other features of maneuverability that change with elevation exert primary influence on competitive ability. These hypotheses will now be evaluated with respect to available evidence.

During aerial competitive bouts, larger-winged S. platycercus males used hovering, vertical ascent, and forward flight, whereas S. rufus used mostly forward flight. The relative costs of these three flights modes have not been rigorously determined for hummingbirds (but see Berger 1985). Nonetheless, S. rufus males appear to be limited in their ability to engage in a broader range of aerial contests. Interspecific differences in flight versatility may be even stronger at high elevations, where S. platycercus increased their use of hovering and vertical ascent but $S$. rufus males decreased their use of these flight modes (fig. 2B). However, the interaction effect between hummingbird group and elevation was not significant in this analysis.

Additional evidence for a threshold hypothesis comes from consideration of wingbeat kinematics and power production. Because the Selasphorus hummingbirds increased wingbeat frequency by $\sim 17 \%$ to lift maximum loads at both sites (fig. $3 A$ ), this variable should not limit burst performance in a manner that changes with elevation. In contrast, the ability to modulate stroke amplitude was affected by altitude, with $S$. rufus males having less ability to increase their stroke amplitude during maximal load lifting due in part to higher baseline requirements during hovering (fig. $3 B$ ). This effect was particularly strong at

high elevations $(B)$. At high elevations, power requirements for free flight hovering increased, whereas burst power availability decreased $(C)$. The burst power that Selasphorus rufus males were capable of producing at the high-elevation site (77.9 W/kg body mass) was substantially lower than the second lowest value ( $88.1 \mathrm{~W} / \mathrm{kg}$ body mass) from $S$. rufus females at the same site. 
Table 5: Three-way ANOVA for the effects of species/gender class, elevation (m), and flight mode (free flight vs. maximum load lifting) on the stroke amplitude of Colorado hummingbirds

\begin{tabular}{lrrrr}
\hline Source & df & \multicolumn{1}{c}{ MSE } & \multicolumn{1}{c}{$F$} & \multicolumn{1}{c}{$P$} \\
\hline Class & 2 & 67.777 & .864 & .428 \\
Elevation & 1 & 523.808 & 6.675 & .013 \\
Mode & 1 & $12,076.300$ & 153.892 & $<.001$ \\
Class $\times$ elevation & 2 & 152.340 & 1.941 & .154 \\
Class $\times$ mode & 2 & 653.418 & 8.327 & $<.001$ \\
Elevation $\times$ mode & 1 & 149.626 & 1.907 & .173 \\
Class $\times$ elevation $\times$ mode & 2 & 62.803 & .800 & .455 \\
Error & 52 & 78.470 & & \\
\hline
\end{tabular}

Note: $\mathrm{MSE}=$ mean squared error.

the higher-elevation site, where the hovering stroke amplitudes are closer to the geometric ceiling near $180^{\circ}$ (Chai and Dudley 1995; Altshuler and Dudley 2003). The hummingbirds do not share a common limit to maximum power production, which is influenced by numerous factors including body mass, wing size (and shape), wingbeat kinematics, and the anatomy and physiology of the muscles. Burst ability for vertical fight performance is limited for all taxa at high elevations but particularly so for $S$. rufus males (fig. 3C). In summary, the observational data from competitive encounters, when combined with the performance data, suggest that the vertical components of flight ability in S. rufus are compromised at high elevations, allowing $S$. platycercus to increase dominance.

Because these data are consistent with a threshold model for burst power availability at high elevation, I will now consider whether an absolute or a relative threshold receives more support. The power margin is the ratio of maximum power production to minimum power requirements and therefore allows for a comparison of relative performance. Reanalyzing the Colorado load-lifting data in terms of powers margins revealed that both elevation and species/gender main effects were significant $(P<$ .001 in both cases). The $S$. rufus males have lower power margins, and all hummingbird groups exhibit higher power margins at the lower-elevation site. However, the interaction effect between these variables was not significant $(P>.50)$, indicating that the relative performance of these Selasphorus hummingbirds did not change across elevations.

The absolute burst power produced by S. rufus males at high elevations ( $\bar{X}=77.9 \mathrm{~W} / \mathrm{kg}$ body mass) is considerably lower than the next lowest value (that of $S$. rufus females: $\bar{X}=88.1 \mathrm{~W} / \mathrm{kg}$ ), and the ability to generate $>80$ $90 \mathrm{~W}$ of power per kilogram of body mass may represent the absolute threshold for successful competition in this community. Among the Peruvian taxa, only one territory holder (Oreonympha nobilis at $3,090 \mathrm{~m}$ ) had a maximum power value $<85 \mathrm{~W} / \mathrm{kg}$. However, these hummingbirds were one of three taxa holding territories at the site and were subordinate to the other two, both of which had considerably higher burst capacity (table 2).

An important caveat for the mechanical power values presented here is that these are calculated from environmental, morphological, and kinematic measurements together with estimates of the forces produced by unsteady aerodynamic mechanisms of flapping wings (Ellington $1984 a, 1984 b, 1984 c, 1984 d, 1984 e, 1984 f)$. Some of the aerodynamic components, such as the profile drag coefficient, are based on empirical measurements (Altshuler et al. 2004a), but several assumptions remain to be tested and validated. Specific values for mechanical power will be adjusted as the understanding of hummingbird aerodynamics and muscle physiology improves, but such adjustments are likely to have similar influence on power estimates among hummingbird taxa.

As a more general qualification, it is also important to emphasize that competitive dominance is certainly influenced by multiple interacting features of flight morphology and maneuverability and that the load-lifting protocol is a relatively coarse measure that captures only a subset of flight capacity. Although measurements of load-lifting ability reveal important components of flight performance at high elevations, other aspects of maneuverability likely dominate at low elevations where hummingbirds are not otherwise limited by aerodynamic power production. There are clearly many other aspects of maneuverability that have not been measured, including axial components such as forward flight and sideslip as well as the full suite of the torsional components of roll, pitch, and yaw (Dudley 2002). Technological advances are making high-speed video more portable and easier to analyze, and it would be highly productive to film competitive encounters for assessment of specific maneuvers that determine aerial dominance. I will now consider how other components of hummingbird flight and behavior may influence competitive ability.

Table 6: Three-way ANOVA for the effects of species/gender class, elevation $(\mathrm{m})$, and flight mode (free flight vs. maximum load lifting) on the aerodynamic power requirements for burst flight (W/kg, body mass specific) in Colorado hummingbirds

\begin{tabular}{lrrrr}
\hline Source & df & \multicolumn{1}{c}{ MSE } & \multicolumn{1}{c}{$F$} & \multicolumn{1}{c}{$P$} \\
\hline Class & 2 & 281.148 & 2.818 & .069 \\
Elevation & 1 & 545.353 & 5.466 & .023 \\
Mode & 1 & $67,261.786$ & 674.129 & $<.001$ \\
Class $\times$ elevation & 2 & 11.082 & .111 & .895 \\
Class $\times$ mode & 2 & 801.537 & 8.033 & $<.001$ \\
Elevation $\times$ mode & 1 & 920.125 & 9.222 & .004 \\
Class $\times$ elevation $\times$ mode & 2 & 24.050 & .241 & .787 \\
Error & 52 & 99.780 & & \\
\hline
\end{tabular}

Note: MSE $=$ mean squared error. 


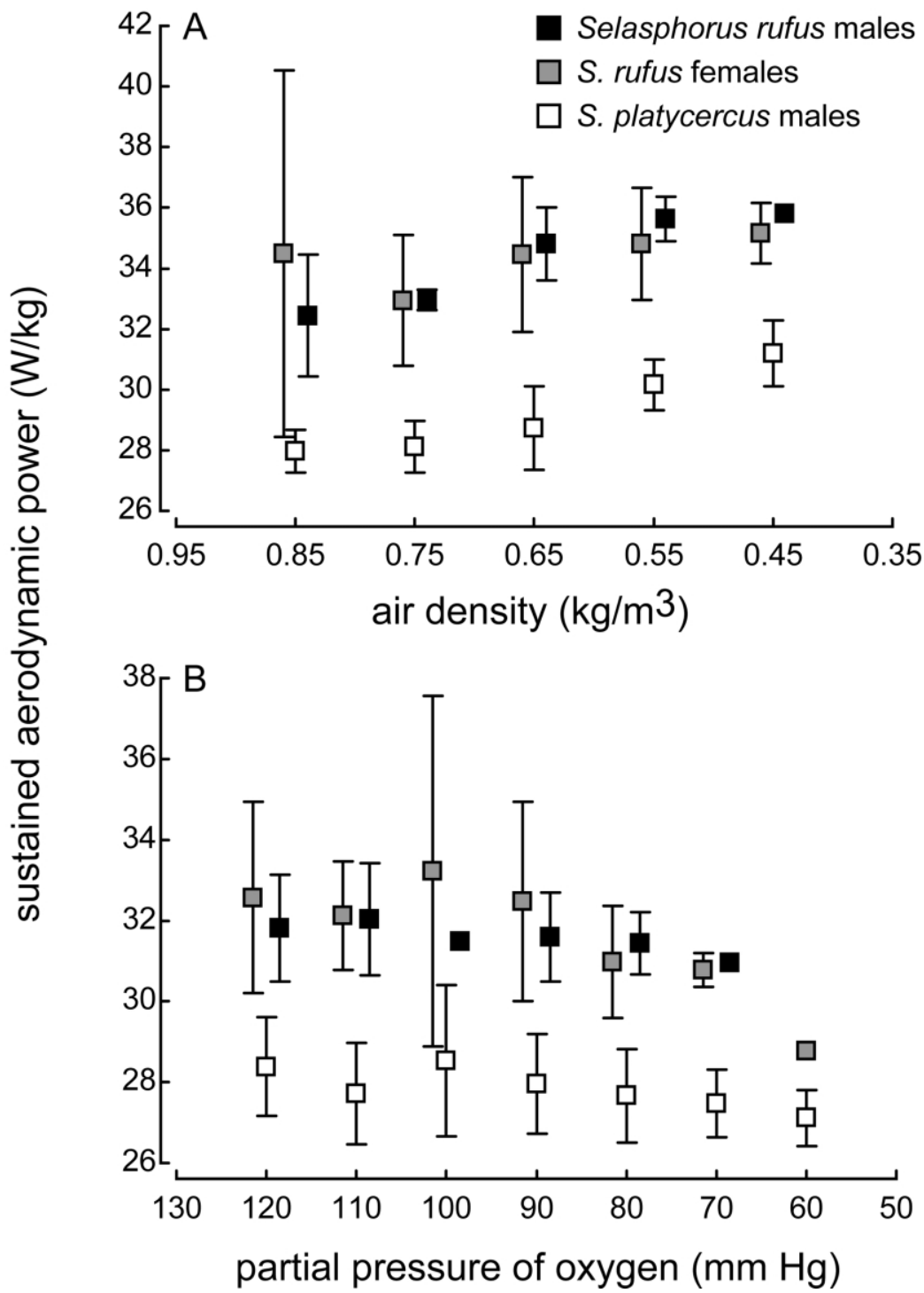

Figure 4: Power requirements of sustained hovering flight did not vary among Selasphorus hummingbirds with experimental changes in air density $(A)$ and oxygen concentration $(B)$. Squares represent mean values of aerodynamic power output, with bars representing SE about the mean. Graphs and included statistics represent the analysis at $2,900 \mathrm{~m}$, but the same trends and significance relationships were also present at $1,875 \mathrm{~m}$.

Although Feinsinger and colleagues (Feinsinger and Chaplin 1975; Feinsinger and Colwell 1978; Feinsinger et al. 1979) placed much of their attention on WDL as a surrogate measure for flight performance, they fully understood that it was aerodynamic power requirements that might ultimately influence competitive behavior. The studies presented here lend support for portions of Feinsinger and colleagues' original hypotheses, namely that aerodynamic power is limiting at high elevations and that differences in flight ability influence competitive dominance. A remaining challenge is to determine the full suite of traits that allow for competitive dominance at low elevations where burst reserves are not limiting for most taxa. It may be that shorter wings and concomitant higher wingbeat frequency in S. rufus males impart a maneuverability advantage, as was previously suggested (Feinsinger and Chaplin 1975; Feinsinger et al. 1979). Addressing this question comparatively would benefit from field studies of more diverse lowland trochilid communities and comparisons of North American migrants in both their temperate and tropical communities.

Another more obvious predictor of competitive behav- 
ior in hummingbirds is that males are almost always more territorial and dominant than females of the same species (Pitelka 1942; Bené 1946; Stiles 1973; DesGranges 1978; Kodric-Brown and Brown 1978; Carpenter et al. 1993c). However, the female Selasphorus in the Colorado Rockies did defend territories and also exhibited increased selectivity at high elevations. These hummingbirds did not reach the $50 \%$ selectivity threshold at high competitor densities, but had it been possible to analyze the females of the two species separately, S. rufus females may have also been assigned dominant status. Regardless, the increased selectivity of female Selasphorus hummingbirds at high elevations represented a further challenge to $S$. rufus males and may have indirectly contributed to increased success in S. platycercus males.

Because S. rufus were migrating, their body masses would have fluctuated considerably over the course of the study (Carpenter et al. 1983, 1993a). The average morphological data for the hummingbirds used in the flight experiments are presented in table 1 of Altshuler and Dudley (2003). Briefly, body mass values were very similar for males and females of both taxa at the lower-elevation site (range of mean values $=3.331-3.404 \mathrm{~g}$ ). All hummingbirds had higher body mass at higher elevations, but values for $S$. rufus males (mean $=3.601$ ) and females (mean $=3.800)$ were slightly higher than for S. platycercus males (mean $=3.360)$. Because induced power requirements are proportional to the square root of body mass (Ellington 1984f), S. rufus pay an aerodynamic cost for building up fat stores during migration (Chai et al. 1999).

The study of locomotor performance in hummingbirds has most often focused on foraging behavior for nectar and, to a lesser extent, for arthropods (Stiles 1995), but another conspicuous feature of hummingbird flight is the elaborate flight displays that males perform to attract potential mates. Males of $S$. platycercus use a combination of climbs and dives in a U-shaped flight pattern that is characterized by considerable vertical ascent (Calder and Calder 1992). The display flights of S. rufus have been

Table 7: Repeated-measures ANOVA for the effects of species/gender class, elevation $(\mathrm{m})$, and air density $\left(\mathrm{kg} / \mathrm{m}^{3}\right.$, repeated measure) on the aerodynamic power requirements for sustained hovering flight (W/ kg, body mass specific) in Colorado hummingbirds

\begin{tabular}{lcrr}
\hline Source & df & \multicolumn{1}{c}{$F$} & \multicolumn{1}{c}{$P$} \\
\hline Class & 2,17 & 14.076 & $<.001$ \\
Elevation & 1,17 & .337 & .569 \\
Class $\times$ elevation & 2,17 & 4.724 & .023 \\
Air density & 2,16 & 36.678 & $<.001$ \\
Air density $\times$ class & 4,32 & 1.062 & .391 \\
Air density $\times$ elevation & 2,16 & .394 & .681 \\
Air density $\times$ class $\times$ elevation & 4,32 & .451 & .771 \\
\hline
\end{tabular}

Table 8: Repeated-measures ANOVA for the effects of species/gender class, elevation (m), and oxygen partial pressure ( $\mathrm{mm} \mathrm{Hg}$, repeated measure) on the aerodynamic power requirements for sustained hovering flight $(\mathrm{W} / \mathrm{kg}$, body mass specific) in Colorado hummingbirds

\begin{tabular}{lcrr}
\hline Source & df & \multicolumn{1}{c}{$F$} & \multicolumn{1}{c}{$P$} \\
\hline Class & 2,13 & 84.800 & $<.001$ \\
Elevation & 1,13 & 33.174 & $<.001$ \\
Class $\times$ elevation & 2,13 & 7.141 & .008 \\
Pressure & 2,12 & 5.360 & .022 \\
Pressure $\times$ class & 4,24 & .846 & .510 \\
Pressure $\times$ elevation & 2,12 & 1.496 & .263 \\
Pressure $\times$ class $\times$ elevation & 4,24 & .639 & .640 \\
\hline
\end{tabular}

described alternatively as a slanted oval (Johnsgard 1983) or, more frequently, as a J-shaped pattern consisting of a climb and dive followed by a leveling off flight (Calder 1993; Hurly et al. 2001). One explanation for these differences in dive description is that $S$. rufus display dives that may change as these hummingbirds migrate. For example, J-type display dives observed in Berkeley, California, by F. I. Ortiz-Crespo were approximately 50\% higher than similar dives recorded 1-2 wk earlier in Los Angeles, California, by F. G. Stiles (F. G. Stiles, personal communication). Thus, $S$. rufus may modulate their flight displays according to flight costs associated with body mass and potential benefits of more costly displays. Taken together with the results from this study, it seems likely that burst performance in hummingbirds is a trait that can be influenced by both natural and sexual selection.

\section{Acknowledgments}

I thank P. Chai and R. Dudley for advice and support throughout all phases of this research. Comments on earlier drafts of this manuscript were also provided by C. J. Clark, M. H. Dickinson, S. Heredia, and F. G. Stiles. I gratefully acknowledge P. Baik, C. Barber, R. Gibbons, A. Gilbert, B. Holmes-Stanciu, C. Lewis, C. Shohet, O. Starry, D. Stephens, and the Earthwatch volunteers for field assistance; the Starsmore Discovery Center and the Rocky Mountain Biological Laboratory for logistical support; and the Colorado Springs School for hospitality. Fieldwork was supported by grants from the National Science Foundation (IBN-9817138 and IBN-992155), the Earthwatch Institute, Sigma Xi, and the University of Texas at Austin.

\section{Literature Cited}

Altshuler, D. L., and R. Dudley. 2002. The ecological and evolutionary interface of hummingbird flight physiology. Journal of Experimental Biology 205:2325-2336. 2003. Kinematics of hovering hummingbird flight along 
simulated and natural elevational gradients. Journal of Experimental Biology 206:3139-3147.

Altshuler, D. L., R. Dudley, and C. P. Ellington. 2004a. Aerodynamic forces of revolving hummingbird wings and wing models. Journal of Zoology (London) 264:327-332.

Altshuler, D. L., F. G. Stiles, and R. Dudley. 2004b. Of hummingbirds and helicopters: hovering costs, competitive ability, and foraging strategies. American Naturalist 163:16-25.

Altshuler, D. L., R. Dudley, and J. A. McGuire. 2004c. Resolution of a paradox: hummingbird flight at high elevation does not come without a cost. Proceedings of the National Academy of Sciences of the USA 101:17731-17736.

Baker, H. G. 1975. Sugar concentrations in nectars from hummingbird flowers. Biotropica 71:37-41.

Bené, F. 1946. The feeding and related behaviors of hummingbirds, with special reference to the black-chin, Archilochus alexandri. Memoirs of the Boston Society of Natural History 9:403-481.

Berger, M. 1985. Sauerstoffverbrauch von Kolibris (Colibri coruscans und C. thalassinus) beim Horizontalflug. Pages 307-314 in W. Nachtigall, ed. BIONA. Report 3. Gustav Fischer, Stuttgart.

Blem, C. R., L. B. Blem, J. Felix, and J. Van Gelder. 2000. Rufous hummingbird sucrose preference: precision of selection varies with concentration. Condor 102:235-238.

Calder, W. A. 1993. Rufous hummingbird (Selasphorus rufus). Pages 1-20 in A. Poole, P. Stettenheim, and F. Gill, eds. The birds of North America. No. 53. Academy of Natural Sciences, Philadelphia.

Calder, W. A., and L. L. Calder. 1992. Broad-tailed hummingbird (Selasphorus platycercus). Pages 1-16 in A. Poole, P. Stettenheim, and F. Gill, eds. The birds of North America. No. 16. Academy of Natural Sciences, Philadelphia.

Carpenter, F. L., D. C. Paton, and M. A. Hixon. 1983. Weight gain and adjustments of feeding territory size in migrant hummingbirds. Proceedings of the National Academy of Sciences of the USA 80:7259-7263.

Carpenter, F. L., M. A. Hixon, C. A. Beuchat, R. W. Russell, and D. C. Paton. 1993a. Biphasic mass gain in migrant hummingbirds: body composition changes, torpor, and ecological significance. Ecology 74:1173-1182.

Carpenter, F. L., M. A. Hixon, E. J. Temeles, R. W. Russell, and D. C. Paton. 1993b. Exploitative compensation by subordinate agesex classes of migrant rufous hummingbirds. Behavioral Ecology and Sociobiology 33:305-312.

Carpenter, F. L., M. A. Hixon, R. W. Russell, D. C. Paton, and E. J. Temeles. 1993c. Interference asymmetries among age-sex classes of rufous hummingbirds during migratory stopovers. Behavioral Ecology and Sociobiology 33:297-304.

Chai, P., and R. Dudley. 1995. Limits to vertebrate locomotor energetics suggested by hummingbirds hovering in heliox. Nature $377: 722-725$

- 1996. Limits to flight energetics of hummingbirds hovering in hypodense and hypoxic gas mixtures. Journal of Experimental Biology 199:2285-2295.

Chai, P., and D. Millard. 1997. Flight and size constraints: hovering performance of large hummingbirds under maximal loading. Journal of Experimental Biology 200:2757-2763.

Chai, P., J. S. C. Chen, and R. Dudley. 1997. Transient hovering performance of hummingbirds under conditions of maximal loading. Journal of Experimental Biology 200:921-929.

Chai, P., D. L. Altshuler, D. B. Stephens, and M. E. Dillon. 1999.
Maximal horizontal flight performance of hummingbirds: effects of body mass and molt. Physiological and Biochemical Zoology 72:145-155.

DesGranges, J.-L. 1978. Organization of a tropical nectar feeding bird guild in a variable environment. Living Bird 17:199-236.

Dudley, R. 1995. Extraordinary flight performance of orchid bees (Apidae: Euglossini) hovering in heliox $\left(80 \% \mathrm{He} / 20 \% \mathrm{O}_{2}\right)$. Journal of Experimental Biology 198:1065-1070.

2002. Mechanisms and implications of animal flight maneuverability. Integrative and Comparative Biology 42:135-140.

Dudley, R., and P. Chai. 1996. Animal flight mechanics in physically variable gas mixtures. Journal of Experimental Biology 199:18811885.

Dunford, C., and E. Dunford. 1972. Interspecific aggression of resident broad-tailed and migrant rufous hummingbirds. Condor 74 : 479 .

Ellington, C. P. 1984a. The aerodynamics of hovering insect flight. I. The quasi-steady analysis. Philosophical Transactions of the Royal Society of London B 305:1-15.

. 1984b. The aerodynamics of hovering insect flight. II. Morphological parameters. Philosophical Transactions of the Royal Society of London B 305:17-40.

1984c. The aerodynamics of hovering insect flight. III. Kinematics. Philosophical Transactions of the Royal Society of London B 305:41-78.

- 1984d. The aerodynamics of hovering insect flight. IV. Aerodynamic mechanisms. Philosophical Transactions of the Royal Society of London B 305:79-113.

- 1984e. The aerodynamics of hovering insect flight. V. A vortex theory. Philosophical Transactions of the Royal Society of London B 305:115-144.

. 1984f. The aerodynamics of hovering insect flight. VI. Lift and power requirements. Philosophical Transactions of the Royal Society of London B 305:145-181.

Feinsinger, P. 1976. Organization of a tropical guild of nectarivorous birds. Ecological Monographs 46:257-291.

Feinsinger, P., and S. B. Chaplin. 1975. On the relationship between wing disc loading and foraging strategy in hummingbirds. American Naturalist 109:217-224.

Feinsinger, P., and R. K. Colwell. 1978. Community organization among Neotropical nectar-feeding birds. American Zoologist 18: 779-795.

Feinsinger, P., R. K. Colwell, J. Terborgh, and S. B. Chaplin. 1979. Elevation and the morphology, flight energetics, and foraging ecology of tropical hummingbirds. American Naturalist 113:481-497.

Feinsinger, P., L. A. Swarm, and J. A. Wolfe. 1985. Nectar-feeding birds on Trinidad and Tobago: comparison of diverse and depauperate guilds. Ecological Monographs 55:1-28.

Garland, T., E. Hankins, and R. B. Huey. 1990. Locomotor capacity and social dominance in male lizards. Functional Ecology 4:243250.

Hammond, K. A., M. A. Chappell, R. A. Cardullo, R. S. Lin, and T. S. Johnsen. 2000. The mechanistic basis of aerobic performance variation in red junglefowl. Journal of Experimental Biology 203: 2053-2064

Hurly, T. A., R. D. Scott, and S. D. Healy. 2001. The function of displays of male rufous hummingbirds. Condor 103:647-651.

Johnsgard, P. A. 1983. The hummingbirds of North America. Smithsonian Institution, Washington, DC.

Kodric-Brown, A., and J. H. Brown. 1978. Influence of economics, 
interspecific competition, and sexual dimorphism on territoriality of migrant rufous hummingbirds. Ecology 59:285-296.

Kuban, J. F., and R. L. Neill. 1980. Feeding ecology of hummingbirds in the highlands of the Chisos Mountains, Texas. Condor 82:180185.

Miller, S. J., and D. W. Inouye. 1983. Roles of the wing whistle in the territorial behaviour of male broad-tailed hummingbirds ( $S e$ lasphorus platycercus). Animal Behaviour 31:689-700.

Mitchell, W. A. 1989. Informational constraints on optimally foraging hummingbirds. Oikos 55:145-154.

Perry, G., K. Levering, I. Girard, and T. Garland. 2004. Locomotor performance and social dominance in male Anolis cristatellus. Animal Behaviour 67:37-47.

Pimm, S. L., M. L. Rosenzweig, and W. Mitchell. 1985. Competition and food selection: field tests of a theory. Ecology 66:798-807.

Pitelka, F. A. 1942. Territoriality and related problems in North American hummingbirds. Condor 44:189-204.

Price, M. V. 1986. Structure of desert rodent communities: a critical review of questions and approaches. American Zoologist 26:3949.

Roberts, W. M. 1996. Hummingbird's nectar concentration prefer- ences at low volume: the importance of time scale. Animal Behaviour 52:361-370.

Sandlin, E. A. 2000. Cue use affects resource subdivision among three coexisting hummingbird species. Behavioral Ecology 11:550-559.

Schoener, T. W. 1986. Mechanistic approaches to community ecology: a new reductionism? American Zoologist 26:81-106.

Stiles, F. G. 1973. Food supply and the annual cycle of the Anna hummingbird. University of California Publications in Zoology 97:1-108.

1995. Behavioral, ecological and morphological correlates of foraging for arthropods by the hummingbirds of a tropical wet forest. Condor 97:853-878.

Stolpe, V. M., and K. Zimmer. 1939. Der Schwirrflug des Kolibri im Zeitlupenfilm. Journal fuer Ornithologie 87:136-155.

Taylor, C. R., and E. R. Weibel. 1981. Design of the mammalian respiratory system. Respiration Physiology 44:1-164.

Wells, D. J. 1993. Muscle performance in hovering hummingbirds. Journal of Experimental Biology 178:39-57.

Associate Editor: Peter C. Wainwright Editor: Jonathan B. Losos 